\title{
Michael Foucault, Power and Assessment in South African Higher Education
}

\author{
Dr Cindy Ramhurry \\ University of Johannesburg, South Africa
}

\begin{abstract}
Assessment policy reform has been a common trend on both international and local levels resulting in significant implications for practice. In line with these trends, South African higher education has adopted a "participatory" framework of assessment. Using a Foucauldian theoretical lens, this paper highlights some of the forms of disciplinary power and control that are carried within the new forms of participatory assessment. Empirical evidence is drawn from assessment practices observed in certain lectures in a South African University. Data is analysed through a Foucauldian lens wherein he forges a connection between disciplinary power, control and regulation (Foucault, 1980). The paper then describes the technologies of disciplinary power that play out within the participatory assessment practices and demonstrates what these technologies of power do to assessors and students when they become involved in it. The paper argues that participatory assessment in some respects epitomizes progressive educational themes yet, when studied with an eye toward power reveals several contradictions and paradoxes.
\end{abstract}

Keywords: Participatory assessment; disciplinary power; higher education; Michael Foucault; Panoptic power; policing. 


\section{on Teaching, Learning and Education}

\section{Introduction}

Postmodernism and its ancillary wave of radical changes such as globalization and progress in information technology have called for a fundamental paradigm shift in the philosophy, structure, and contents of educational policies worldwide (Mockler, 2004). In line with this, assessment policy reform has been a common trend on both international and local levels resulting in significant implications for practice (Berry and Adamson, 2011). In traditional processes of assessment; the assessor is seen as a detached 'eye' and views the testing event from an objective distance, outside the universe of the person assessed (Dikli, 2003). That distance is believed to assure the objectivity of the score. This perspective has been criticized on account of its preoccupation with measurement rather than the learning itself (Gipps, 2011).

Postmodernists advocate a participatory perspective which is believed to provide greater empowerment in learning (Hargreaves, 2002; Gardner, 2012). This perspective embodies a quest to foster empowerment through students becoming self-regulating and active participants in their own learning. In line with the post-modernist approach, Higher Education assessment policies introduced in South Africa are characterised by a "participatory" approach: they prioritise collaborative and self-directed inquiry using democratic and dialogical assessment strategies such as self-, peer- and group- assessment strategies (DoE, 2000).

The relevance and pervasiveness of postmodernism in most spheres of human existence is such that it should not be ignored in educational assessment practices (Hargreaves, 2002). The application of one of these postmodernist doctrines and its practice to educational assessment practices is central to this paper. The paper generates the problematic of power in participatory assessment practices. Employing a theoretical framework which is grounded in a conception of power based on the work of Michel Foucault (1977), the paper highlights some of the tensions evident in participatory assessment practices in a South African University.

The significance of this paper lies in its contribution towards an understanding of power relations in participatory assessment practices in higher education. Moreover, this study contributes to such understanding from a unique empirical base: it shows how power relations 


\section{on Teaching, Learning and Education}

are central in the micro-level enactment of pedagogy. An understanding of power relations in pedagogy which enables new points of intervention to be explored, has the potential to make a substantial contribution to educational theory, policy, and practice.

\section{Why Power and assessment?}

Almost all questions in educational assessment it would seem are more or less connected with the issue of power. In fact, "Power has become one of the central concepts of the social and human sciences per se" (Clegg 1989, xviii). In terms of existing empirical studies of pedagogy, while there is a vast body of literature on pedagogy, there is little empirical work that attends both to issues of pedagogy and to issues of power. Although Bourdieu (in his work with Passeron and others) and Bernstein provide the most sophisticated and detailed analyses of power and pedagogy, even their work on this topic lacks a substantial systematic empirical base (Gore, 2002). Bernstein's (1990) theory of power is derived from mapping societal power relations and showing that pedagogy is implicated in the production of those relations through its rules (regulative, distributive, contextualising, etc.). Bourdieu and Passeron's (1977) view of pedagogy as symbolic violence is based on Weberian notions of authority and the emphasis is on how large discourses are imposed on, and taken up by, the body (Gore, 2002).

Foucault's (1977) conception of power, on the other hand, goes on to demonstrate how the power relations inherent to pedagogy govern and regulate bodies and knowledge and to show that discourses are constructed out of pedagogy itself. From Foucault's (1977) perspective, power is not simply the imposition of one will on another. Its subtleties and nuances are taken into account in a way that acknowledges that there is much more going on than the imposition or reproduction of broader societal power relations. In terms of existing studies of assessment, while there is a vast body of literature that concentrates on macro-practices of assessment, very little energy is dedicated to the micro-level of analysis. This study bridges that gap by examining micro-practices of power in assessment at the level of higher education.

Assessment practices at the level of higher education are therefore regarded as both central and peripheral to this paper. The unveiling of technologies of power in assessment practices occurs, 


\section{on Teaching, Learning and Education}

here, on two levels: locally, in a study of assessment in university classrooms, and discursively, on the value of a Foucauldian analysis of power for educators. The two stories work concurrently. Foucault's analysis of productive power provides the theoretical grounding for a study of power operating in participatory assessment practices. In turn, the study of power serves to illustrate gaps in the predominant ways power is addressed in participatory assessment contexts. Rather than offer a full-scale genealogy of assessment practices, this paper contributes a genealogical snapshot of one particular transition in teaching practice, namely the shift from so-called 'traditional' assessment to 'participatory' assessment frameworks of organization.

\section{Background to the study}

The study was conducted at the University of Suburbia (pseudonym), located in the suburbs of a very large, metropolitan area in South Africa with a human population numbering in the millions. The observations at University of Suburbia were conducted within three lecture rooms in the subject area of Communication Skills. The key participants in this study were three lecturers and their respective students. Although a small sample limited any possibility for generalizability, this case study research dug deeper and looked more broadly than would be conceivable with some commonly used quantitative methods.

Data reduced from video-recorded observations resulted in thematic perception generalizations toward assessment practices at University of Suburbia. For the purposes of this paper only participatory assessment practices is given priority. Therefore, this paper looks closely at the configurations of power inherent in participatory assessment practices and the kinds of subjects it produces. The question that guided this research was: How are patterns of power currently determining the lecturers' and students' experiences of participatory assessment, and constructing their images of self, others, and the world? 


\section{on Teaching, Learning and Education}

\section{Theoretical framework}

The theoretical framework for the paper is grounded in the conception of disciplinary power based on the work of Michel Foucault (1977). Foucault's (1977) conception of power relations requires a focus on the mechanisms of pedagogy rather than on individuals or groups who might traditionally have been seen as holding power. While other scholars and researchers in education have engaged with some of Foucault's ideas (e.g., Ball, 1990; Marshall, 1989 ), this paper aims to demonstrate, rather than assert, the applicability of Foucault's thought to the study of power.

Foucault described disciplinary power as circulating rather than being possessed, productive and not necessarily repressive, existing in action, functioning at the level of the body, often operating through 'technologies of self', that is, that individuals are active in their own subjection. Foucault's concept of disciplinary power explicitly shifts analyses of power from the 'macro' realm of structures and ideologies to the 'micro' level of bodies. He argued that unlike the sovereign power of earlier periods, disciplinary power functions at the level of the body:

In thinking of the mechanisms of power, I am thinking rather of its capillary form of existence, the point where power reaches into the very grain of individuals, touches their bodies and inserts itself into their action and attitudes, their discourses, learning processes and everyday lives. (Foucault, 1980, p.39) (emphasis added)

Foucault (1980) elaborates the invisibility and pervasiveness of disciplinary power in modern society: "The eighteenth century invented, so to speak, a synaptic regime of power, a regime of its exercise within the social body rather than from above it" (p.39).

Central to the notion of disciplinary power, is Michel Foucault's (1977) description of Jeremy Bentham's panopticon. This was a system of surveillance originally designed with penal institutions in mind, but that has become a metaphor for the much broader and more subtle intrusion of observation and record-keeping techniques into more and more areas of social life (Foucault 1977: 200-209; Foucault, 1980). The basic idea of the panopticon is straightforward: a central tower or structure has windows on all sides, and it is in turn surrounded by a ring of 


\section{on Teaching, Learning and Education}

cells occupied by the inmates, the open sides facing inward. Observers can look out in any direction, at any time, to see what any inmate might be doing. Furthermore, since the inmates cannot see into the central observation tower, every window or observation point does not, in fact, need to be staffed all the time; the possibility of being observed has a deterrent effect even when inmates are not in fact being observed. And, still further, as inmates become accustomed to this environment, and to the routine of assuming that they are being observed at any/every time, it becomes less important for the observation tower to be staffed at all; the structure of the environment is what exerts control, as people internalize changes to their habits and movements without remembering the original circumstances that necessitated them. The panoptic condition becomes part of the identity of an inmate (" a madman, a patient, a condemned man, a worker or a schoolboy" (Foucault, 1977: 200)).

Several important conclusions follow from Foucault's description of the Panopticon. One of these is that, with practice, the panoptic mechanisms of surveillance tend to become more pervasive: for example, few people even notice any longer how frequently they are monitored through partially hidden video cameras (from the bus, to the bank, to the store, to the parking lot, to the elevator). This is one of the central themes of Foucault's (1977) book, Discipline and Punish: that as the mechanisms of surveillance and control become more subtle and 'humane', they become more extensive; they actually become more controlling in their effects, but with less complaint.

The above theoretical tools, derived from Foucault's work, were used to identify techniques of power within participatory assessment practices in University of Suburbia. Given clear patterns evident from the qualitative analysis of these data, an attempt was made to analyse, in a more contextualised way, the object of the particular practice of power, the specific way in which the technique of power was enacted, the direction of the exercise of power, and any reactions or consequences evident. 


\section{on Teaching, Learning and Education}

\section{Discussion of findings}

Findings revealed that the lecturers' assessment practices consistently took on an ambiguous character. While it appeared on the surface as though the assessment practices were "participatory" in nature, the analysis found them to be implicitly "traditional" by their characteristic emphasis on measurement and control of space and time. These patterns of ambiguity are discussed under three themes:

\section{Abandonment of participatory assessment practices}

2. A concern with "Marks"

3. My presence in the lecture

\section{Abandonment of participatory assessment practices}

A noticeable trend that underpinned all three lecturers' practices was their initial attempts to use participatory techniques of assessment, and a subsequent abandonment of these for traditional assessment practices. The discourses reflected within Mary's lectures are exemplary of this trend. Mary made a concerted effort to "nurture" her students into the new culture of participatory assessment. She mentioned that she would be using peer assessment strategies and spent some time in her initial lectures to explain to students what was expected of them. The implementation of the peer assessment into the lecture however, was met with dangerous consequences.

It seemed that the peer assessment introduced a more relaxed, casual and rowdier social atmosphere into the lecture. There was more student chatting, walking around and louder conversations. The lecturer appeared to be flustered by the student activity and shouted to them to be quiet. Her regulative control of the students' increased and reached extreme proportions towards the end of the lecture. I bore witness to the frustrations she experienced from her students' reluctant responses to her attempts. Her eventual response was a form of concealed rejection of participatory assessment modes for the "safer" traditional methods of assessment. She asked the students to return to their seats, to stop chatting and to focus on her slides. Although she completely side-lined the peer assessment activities, she continued to "show" both verbally and non-verbally that she was still on board with the participatory methods 


\section{on Teaching, Learning and Education}

suggested by the University's Assessment Policy. The lecturer's verbal and non-verbal "displays" seemed to have been constructed for the judgement of external audiences. In this case, it was myself, the researcher, and perhaps the observing "eye" of the University itself.

It could be argued that the "new" assessment practice and its unique social demands interfered with the order and formality that the lecturers had established in their traditional classroom arrangements. It was obvious that the lecturers fore-grounded the 'controlling functions' of the assessment rather than its 'educational purposes.' In serving the social control function, the lecturers, themselves both transmitting and being acted on by power, become part of the process by which they disciplined their students, and they themselves are controlled by the same forces (Foucault, 1977). From a Foucauldian perspective, such displays of behaviour can be seen as forms of social control, and perhaps likened to a two-edged sword; the students are controlled by the lecturers, but both lecturers and students are controlled and shaped by other forces in ways much more subtle and difficult to detect.

In this analysis, the notion of governmentality was a strong factor of contingency. This context showed the forces of governing being channelled strategically through the discourse of accountability in Policy documents. It could be argued that the pressure to conform to university expectations, led to Mary's putting up of appearances where she indicated that she was doing her job in the way that was "expected". One could see this as a "strategy" utilized by the University to make lecturers govern themselves. In Foucault's view, this is the working of power in its disciplinary form. Conformity is not the result of an overt force that visibly bends the will of those subject to its operation; conformity results from the constant working of invisible constraints that bring us all toward the same 'normal' range of practices and beliefs (Foucault, 1977).

\section{A fixation with "Marks"}

It was noted that all three lecturers mentioned the word "marks", "tests" and "examination" several times during their lectures. The use of these words and what they represented produced both positive and negative forms of energy for students and lecturers alike. For example, in 


\section{on Teaching, Learning and Education}

Jill's class, the students were going about a peer assessment task and were clearly enjoying it (evident from their body language and articulations). This may be perceived as positive in the sense the lecturer's plans were taking shape as students were co-operative. However, the lecturer started to display certain signs of anxiety relating to the way the students approached the task. It was almost as though she felt in-secure with the lack of formality surrounding the assessment and its formal implications: She constantly reminded that them that the assessment was important: "Now guys remember...this is going into ...your...um...semester marks hey....so do it properly." The sense was conveyed that the reference to marks, tests and examination, and what they authorised, were used as tools to help the lecturers to sustain their students' interest in the lecture. Perhaps the lecturers experienced fears of losing control of their students as well as the lecture, when using participatory assessment techniques.

The metaphorical idea of "policing" was manifested in this theme, by the forms of accountability it imposed on participants in the study. Accountability, in the form of covert and overt external expectations from the university, was a strong factor of contingency. Expected records of marks, expected norms for learner and teacher conduct, expected exemplifications of assessment competence (e.g. semester marks, examinations, etc.) were found to impact on lecturers' participatory assessment practices, with the effect of constantly drawing them back to the "safety" of traditional assessment practices. At no point was the "return" to traditional assessment ever explicit, it remained a concealed discourse, with outer appearances of participatory assessment being displayed. An important question of pedagogical authenticity is raised - the "performances" made it difficult to determine 'real' assessment of learning.

\section{The observer's gaze}

All three lecturers behaviour and practices suggested an internal struggle when it came to assessment. While they seemed to be on board with participatory assessment modes, they all reflected excessive concerns with the control of lecture-room space, lecture time and the classification of the assessment task. For example, Jill did not allow students to move around the lecture hall and often presented rigid and unreasonable time frames for students to work within. Thom similarly displayed an excessiveness in controlling the social space students 


\section{on Teaching, Learning and Education}

worked in, also spending a great deal of time classifying the test in terms of the assessment structure provided to students in their Learning Guide. On the part of all three lecturers a sense was conveyed that participatory assessment activity was "forced" into the lectures. There was much within the data which suggested that lecturers were pressurised by my "gaze" to windowdress what was expected of them. My presence in the classroom could thus be construed as a gaze which not only invaded the lecturers' and students' privacy, but also seemed to serve as an additional form of surveillance by the educational system.

\section{Participatory assessment as a form of panoptic power}

The discourses underpinning all three themes reflect many characteristics of Foucault's (1977) concept of panoptic power. There was a strong suggestion that the "participatory" performances in assessment were constructed for the purposes of my judgement. Implicitly, the lecturers' concern for my work also had something to do with what I recorded about their practices. From this perspective, one could argue that the participatory assessment activities were "forced" into the lectures to satisfy external and internal "gazes". The "internal gazes" could have been constituted by my presence as observer in the lesson. The lecturers' needs to reflect their receptivity to new assessment practices was invoked by my "gaze". Could this perhaps have been an external gaze constituted by the accountability lecturers faced in terms of university regulations?

These contingencies can be traced to covert and overt "expectations" of assessment suggested by policy documentation. A key point is that the intersecting "gazes" of accountability created tension in terms of how lecturers managed their roles in assessment. Accountability appears to be a factor of contingency in this theme. Their efforts to "show" that they were engaging in participatory assessment practices, indicated that they reconstituted themselves as a successfully conforming to the participatory assessment philosophy. From this perspective, my panoptic role as "guard in the tower" of a new "will to truth" (participatory assessment) comes across as a strong possibility.

The study also found that the university's surveillance was so enveloping that even when there were no physical surveillance mechanisms present, lecturers' practices were regulated. In these cases lecturers appeared to have been intimidated into displaying assessment practice in ways 


\section{on Teaching, Learning and Education}

that would be regarded as 'correct' in assessment documentation. On closer analysis, it seemed as though the surveillance system had created a context where the lecturers became an additional driving force of the external accountability system rather than governors of their individual potential. Thus, in an unintended way, through my well-intended research needs of observing lecturers', together with the participants' trust, I reinforced the strength of the accountability system.

This genealogical analysis unearthed an intricate picture of struggles regarding the notion of participatory assessment. In their practices of participatory assessment the lecturers found the power relations too extreme, rejecting them for practices in which they secured dominance over the relationship between themselves and their students. It was highly apparent that all three lecturers opted for the familiarity and safety of their traditional assessment roles. The lecturers' resistance to participatory assessment practices could be linked to macro factors. On a macro level, the lecturers are constituted as agents who enacted the university's policies of governance. All three lecturers "composed performances" of participatory assessment to satisfy certain forms of accountability to the university.

From Foucault's (1977) theoretical perspective of power, it could be argued that there were subtle subjectivizing and normalising strategies that continually diverted the course of participatory assessment. The apparent "participatory" exterior was used by lecturers as a veil to substitute the obvious disciplinary strategies of traditional assessment. One got the sense that participatory displays were constructed to satisfy the expectations of an observing "gaze". It was apparent that all three lecturers employed participatory assessment methodologies primarily as a form of window dressing.

\section{Discourses of Performativity}

Findings in this study showed that a powerful discourse of performativity, pervaded the assessment practices of the lecturers observed. The literature refers to the practice of composing performances as a "Performativity discourse" (Jeffrey, 2002; Ball, 2003). It would seem that a performativity discourse is not an unusual phenomenon in the teaching and learning context. The literature acknowledges the performativity discourse that "currently pervades lecturers' work" (Jeffrey, 2002: 1). Ball (2003: 222) speaks of these "performances" as acts of lecturers' game-playing, cynical compliance, or "enacted fantasy." He suggests that such 


\section{on Teaching, Learning and Education}

constructed performances are displayed for the benefit of external judgement. Ball (2003: 224) points out below, that they may not always be far from the truth: Fabrications are not 'outside the truth' but neither do they render simply true or direct accounts - they are produced purposefully in order 'to be accountable'. Truthfulness is not the point - the point is their effectiveness, for inspection or appraisal, and in the 'work' they do 'on' and 'in' the organization. One can see the relevance of the ideas on performativity, in this study: both lecturers put into place certain measures to satisfy forms of accountability.

At many points, the lecturers' assessment "performances" complied at face value with participatory expectations of Assessment Policy Documents. The sense was conveyed that the lecturers put up performances in order to gain a favourable evaluation of their practices, from external bodies. Lyotard (1984: 46), who has written extensively on the concept of performativity, speaks about it operating in conjunction with a "market discourse". He argues that society is "obsessed" with competency and efficacy which operates in terms of an "input/output ratio" (Lyotard, 1984: 88). His point, which is captured below, is that schools, like businesses become open to judgement in terms of their outcomes and performance: ...the goal is no longer truth, but performativity - that is, the best possible input/output equation. The University and/or company must abandon the idealist and humanist narratives of legitimation in order to justify the new goal: in the discourse of today's financial backers of research, the only credible goal is power. Scientists, technicians and instruments are purchased not to find truth, but to augment power.

In Lyotard's (1984) view, lecturers often produce 'evidence' of their efficiency to meet with external demands or expectations. Such "productions" are often responses to coercion attempts that work through overt and covert forms of surveillance (Lyotard, 1984: 63-64). In terms of the overt forms of coercion, he points us to the monitoring of data by the Government. Covert coercion is characterised by implicit expectations put - 303 - into place to regulate lecturers. Ball's (2000: 2) work quoted below conveys this as a "game" with certain implicit rules: There is not so much, or not only, a structure of surveillance, as a flow of performativities both continuous and eventful. It is not the certainty of being seen that is the issue. Instead it is the uncertainty and instability of being judged in different ways, by different means, through different agents; the 'bringing-off' of performances - the flow of changing demands, 


\section{on Teaching, Learning and Education}

expectations and indicators that make us continually accountable and constantly recorded. Ball conveys the idea of performativity as dependent the performance and the ways performances are interpreted. The Performativity discourse unveiled by this analysis has relevance to the ideas about power Foucault conveys in the lecture entitled, Omnes et Singulatim: Towards a Criticism of Political Reason (1981). In this lecture Foucault (1981: 227) writes about the notion of "pastorship" by the university. He refers to the idea of "police" - indicating the apparatuses of security that are employed as "governmental techniques of the modern university" (Foucault, 1981: 250) He discusses the role of pastoral power as a technique which is subtly diffused throughout society with the intention of improving lives (Foucault, 1981: 235). Another was the question of whose expectations being prioritised- those of the learner, the teacher, or those of the university? Foucault's idea of "pastorship" by the university is a complex matter particularly within the South African assessment context, where accountability and visibility are perceived as highly valued discourses.

Within the new context of participatory assessment, policy holds lecturers accountable to meeting assessment criteria and learning outcomes, pursuing a performance assessment framework and rigorously documenting marks. One can understand South Africa's need for more observable or noticeable forms of evaluation. Perhaps such a system serves as a means of aligning education to the ideals for greater transparency. While the previous assessment system might have been covert in character, there is the impression conveyed, that by adopting a more "public" approach regarding learner performance and decisions relating to its quality, assessment would become more productive. We emerge with the idea that in the new South African Assessment approach, accountability, has noble pedagogic intentions and its policies are widely accepted. We appreciate that stronger forms of accountability are needed to stabilise the current unsteady ground of the South African Assessment system. In this case- lecturers' meeting of expectations is necessary to the goals of learning. However, it is when "meeting expectations" happens at the expense of "real" learning, that one becomes concerned.

One gets the sense that the actual complexity of participatory assessment is backgrounded in the many petty and detailed practices in and around it. Some of these include, the conflicting subjectivities on the part of both lecturers and students; the impact of the university's semester mark system on participatory assessment; the impact of oppositional discourses in existence 


\section{on Teaching, Learning and Education}

beneath the surface of university life; the panoptic hold those in power have over individual bodies, and the extent to which normalizing practices, both from sources external and internal to the university, impact on participatory assessment practices.

\section{A resulting hybridity}

Performativity in participatory assessment practice has been revealed in this genealogical analysis as an important discourse. These performances reflected that lecturers were absorbing the new participatory assessment into their practices despite their possible overt opposition to it. The lecturers' engagements with performativity were perhaps a product of their struggles to deal with participatory assessment. At the same time they could also be seen to be producing new, hybrid elements of assessment which can feed into the evolution of more complex participatory assessment pedagogies. The discourse of control which currently operates in the curriculum has been described in creative ways in recent research. For example, in the book "Curriculum Visions" (2002), Doll and Gough (2002: 34) describe it metaphorically as a ghost who haunts the curriculum: Control is actually embedded in the concept of curriculum. Control is not only the ghost in the clock of curriculum -- to use the predominant modernist, mechanistic metaphor -- it is the ghost which actually runs the clock. It is time to put this ghost to rest ... and to liberate curriculum to live a life of its own. These authors raise the issue of our need to liberate ourselves from the oppressive demands of assessment in the classroom, particularly that which compares and ranks students in competitive rather than collaborative ways. The analysis has shown how both lecturers exercised power and were in turn acted on by power. The lecturers were part of a system where they disciplined their students and were themselves disciplined by similar forces. In the face of this host of conflicting forces, one can understand how both lecturers' attempts to practice participatory assessment might have been rejected for traditional methods.

\section{Conclusion}

This study found that participatory assessment at University of Suburbia existed against a background of extreme conflict and tension. It was complicated by several contingencies and unexpected factors and was continually moved out of balance, by the impact of the discursive struggles within it. This analysis has shown the totalizing hold those in power have over individual bodies. It has provided an understanding of how multiple realities operate upon 


\section{on Teaching, Learning and Education}

bodies to render them as subjects. It has shown us some of the "dangerous" ways that subjectivity is constructed within participatory assessment practices. Ideas that have emerged from this research have highlighted the need to point to just how unsatisfactory the victory account of participatory assessment is, given my study of how it elides the complex issues of power going on. In terms of the way forward, we recognize that we can never return to earlier system of assessment. Nor can we use a form of participatory assessment that may liberate us from the panoptic effects of power. Foucault's (1926-1984) arguments show that power may not be controlled by one's intentions: any specific discourse will generate resistance as it meets competing discourses.

As we have seen in this study, it is not the "right" use of power or a specific technique of assessment that will effectively resist the effects of discipline and normalization. Rather, we can take notice of dominant discourses, and break down systems that claim to tell "the truth" about us. In other words, although we cannot prevent our participatory assessment discourses from generating productive power, we can, actively cultivate an awareness of the dangers. Perhaps we must work to better understand the concepts of choice, voice, and multiplicity of roles within the discourse of participatory assessment. I offer these recommendations with hope and respect, in recognition of our collective and individual voices.

On the whole, this study has demonstrated that Foucault's theory, methods and the model constructed for this study are relevant, valuable and effective when investigating power in participatory assessment. By using Foucault's (1977) suggestions for discourse inquiry, this study has revealed the "different things" that exist within participatory assessment practices. As Foucault (1980: 142) puts it: The genealogist finds that there is something altogether different behind things: not a timeless essential secret, but the secret that they have no essence or that their essence was fabricated in a piecemeal fashion from alien forms.

The threads that have connected the sections of this research are the three sub-questions which guided the study. These are: 1) What kind of power relations exist within participatory assessment practices? 2) Is it possible for educators to act and think differently about their assessment practices? 3) How can educators create openings in assessment which will allow their students to grow and develop? The question of whether I have illuminated the power within participatory assessment practices through genealogical analysis at University of 


\section{on Teaching, Learning and Education}

Suburbia is a reasonable one. The discussion of the power themes related to each of the extracts, has revealed certain ways in which participatory assessment practices position lecturers and students in the classroom.

One of the questions dealt with the issue of whether it is possible for assessors to act and think differently about their assessment practices. Following this piece of genealogical work, alternatives are indeed possible in participatory assessment. This paper advocates a vision of the role of participatory assessment as one which acknowledges the importance of relationship between the assessed and the assessor. It argues that assessors need to value the relationships with students and create opportunities to not just listen but to actually hear their voices. The paper argues further that conscious attempts need to be made by assessors to question the notion of accountability and find ways to avoid being dominated by the "system". Furthermore, assessors need to better understand the concepts of choice, voice, and multiplicity of roles within the discourses of participatory assessment.

\section{References}

Ball, S. J. 1990. Introducing Monsieur Foucault. In Foucault and Education:

Disciplines and Knowledge (pp.1-10). London: Routledge.

Ball, S. J. 2000. Performativities and fabrications in the education economy: towards the performative society. Australian Educational Researcher, 27(2), pp. 1-23.

Ball, S. J. 2003. The teacher's soul and the terrors of performativity. Education Policy, 18(2), pp. 215-228.

Berry, R. and Adamson, B. eds., 2011. Assessment reform in education: policy and practice (Vol. 14). Springer Science and Business Media.

Bernstein, B. 1990. The structuring of pedagogic discourse. Volume IV. Class, codes and control.

Bourdieu, P., and Passeron, J. 1977. Reproduction in education, society, and culture. Beverly Hills, CA: Sage.

Clegg. S. R. 1989. Frameworks of Power. London: Sage. 149 


\section{on Teaching, Learning and Education}

Department of Education. 2000. Education for All: The South African Assessment Report. Pretoria: Department of Education.

Dikli, S. 2003. Assessment at a Distance: Traditional vs. Alternative Assessments. Turkish Online Journal of Educational Technology-TOJET, 2(3), pp.13-19.

Foucault, M. 1977. Discipline and Punish: The birth of the prison. New York: Vintage.

Foucault, M. 1980. Power/Knowledge: Selected Interviews and Other Writings 1972-1977, edited by Colin Gordon, Harvester, London.

Foucault, M. 1981. Omnes et Singulatim: Toward a Criticism of 'Political Reason. In The Tanner Lectures of Human Values II (pp. 223-54). Salt Lake City, UT: University of Utah Press.

Jeffrey, B. 2002. Performativity and primary teacher relations. Journal of Education

Policy. Accessed 28 January, 2018 from

http://www.informaworld.com/smpp/title $\sim$ content=t713693402 $\sim \mathrm{db}=$ all $\sim$ tab $=$ issueslist $\sim$ branc hes $=17-\mathrm{v} 1717(5)$

Gardner, J. ed., 2012. Assessment and learning. Sage.

Gipps, C., 2011. Beyond Testing (Classic Edition): Towards a theory of educational assessment. Routledge.

Gore, Jennifer M. 1996. 'Understanding Power Relations in Pedagogy'. Paper presented at the Annual Conference of the Australian Educational Research Association, Singapore.

Hargreaves, A. 2002. "Perspectives on Classroom Assessment." In American Educational Research Journal, 39(1), 2002, 69-100.

Lyotard, J. L. 1984. The Postmodern Condition, G. Bennington and B. Matsuda (Trans.) Manchester: Manchester University Press.

Marshall, J.D., 1989. Foucault and education. Australian journal of education, 33(2), pp.99113.

Mockler, N. and Sachs, J. 2002. 'A Crisis of Identity? Lecturer Professional Identity and Evidence Based Practice'. Paper presented to the Annual Conference of the Australian Association for Research in Education. Brisbane, University of Queensland, December 2002. 